\title{
ELABORAÇÃO DE AÇÕES EDUCATIVAS PARA O PÚBLICO INFANTIL SOBRE OS DIREITOS E DEVERES DA POPULAÇÃO NO TRÂNSITO POR ESTUDANTES DE ENGENHARIA CIVIL DA UFPR
}

Letícia Wan-Dall Gonçalves - leticiawandall@gmail.com

Universidade Federal do Paraná - Curso de Engenharia Civil

Avenida Coronel Francisco Heráclito dos Santos, 210

81531-970 - Curitiba - Paraná

Gabriel Paula Soares Gomes de Souza-gabrielpsgsouza@gmail.com

Universidade Federal do Paraná - Curso de Engenharia Civil

Avenida Coronel Francisco Heráclito dos Santos, 210

81531-970 - Curitiba - Paraná

Márcia de Andrade Pereira Bernardinis - profmarcia.map@gmail.com

Universidade Federal do Paraná - Departamento de Transportes

Avenida Coronel Francisco Heráclito dos Santos, 210

81531-970 - Curitiba - Paraná

Resumo: $O$ trânsito caótico nas cidades brasileiras tem feito cada vez mais vítimas por ano, em especial entre a população jovem. O mau funcionamento do trânsito deve-se, em parte, ao desconhecimento da população acerca das legislações vigentes, bem como de seus direitos e deveres conforme cada modal. Visando contribuir para a redução no número de acidentes de trânsito na cidade de Curitiba (PR) e região metropolitana, o PET Engenharia Civil UFPR propõe o projeto Mitos e Verdades sobre o Trânsito. Os discentes utilizam os conhecimentos adquiridos nas disciplinas ligadas à área de Engenharia de Transportes do curso de Engenharia Civil para construir um livro didático para crianças de 6 a 10 anos e atividades práticas a serem aplicadas em escolas públicas da cidade. Como resultado, além do livro, os estudantes vivenciam uma experiência extraclasse articulada de ensino, pesquisa e extensão com um forte viés social, pouco comum nas estruturas convencionais de ensino, que agrega à sua formação tanto competências técnicas quanto competências transversais, ambas igualmente fundamentais na formação do engenheiro do amanhã.

Palavras-chave: Educação para o trânsito. Engenharia de Transportes. Programa de Educação Tutorial.

\section{INTRODUÇÃO}

O contexto do trânsito brasileiro não corresponde às expectativas para a contemporaneidade. Atualmente, o tempo de deslocamento e os índices de acidentes são altos, indo na contramão da segurança viária. Em 2010, houve mais de 55 mil vítimas em acidentes de trânsito em Curitiba, e dessas quase dois mil foram a óbito (Detran-PR, 2010). Entende-se que tais números devem-se em parte ao baixo investimento das autoridades políticas com relação ao um planejamento urbano estratégico. Contudo, muitos acidentes podem ser evitados através da informação pelos cidadãos a respeito das leis de trânsito, a partir de políticas públicas de educação nessa esfera. 
A fim de contribuir para a mitigação dos acidentes de trânsito, o PET Engenharia Civil UFPR, em conjunto com o Grupo de Estudos em Transportes da UFPR (GET) e a $\operatorname{Prof}^{a} \mathrm{Dr}^{\mathrm{a}}$ Márcia Bernardinis, do Departamento de Transportes da UFPR, colocou-se como agente precursor de mudanças no cenário anteriormente citado. Com isso, criou-se o projeto "Mitos e Verdades Sobre O Trânsito". Esse projeto possibilitou também o aprimoramento na formação de alunos ligados ao curso de Engenharia Civil ao atendimento da tríade na sua formação: Pesquisa, Ensino e Extensão, visto que os alunos participantes do projeto puderam ter contato com essas três vertentes do processo de formação profissional.

O projeto foi dividido em etapas para alcançar a construção de um material educativo destinado a crianças de 6 a 10 anos, contendo dados e curiosidades a respeito dos modais urbanos de transporte e como se portar na utilização de cada um deles. Com isso, planejou-se também a distribuição desse material e a realização de atividades em escolas de ensino fundamental da cidade de Curitiba, entendendo que assim a disseminação do conhecimento aconteceria das crianças para os adultos.

Diante do contexto apresentado, entende-se que o projeto é de grande importância para a comunidade, uma vez que essas questões muitas vezes não são discutidas no âmbito escolar. Em vista disso, este artigo tem como objetivo a explanação da elaboração do projeto, além da formação do grupo de trabalho em conjunto do GET e da Prof ${ }^{a}$ Márcia Bernardinis. Este artigo também se propõe a relatar o processo criativo do livro "Mitos e Verdades sobre o Trânsito" e projetar seus impactos na sociedade.

\section{APRESENTAÇÃO DO PROJETO}

Em seu artigo "A criança, o adolescente e o trânsito: algumas reflexões importantes", de 2012, Jorge e Martins elucidam que, mesmo com a implementação do Código de Trânsito Brasileiro em 1998, o Brasil ainda tem um dos trânsitos mais violentos do mundo, sobretudo para a população jovem. Isso se deve a fatores sociais, econômicos e educacionais, além do fato de que as crianças e adolescentes são mais vulneráveis a sequelas graves que podem levar à morte, principalmente em atropelamentos. As autoras apontam, ainda, que o desconhecimento das normas de trânsito, tanto pelos jovens quanto por seus responsáveis, potencializa esses números, além de contribuir para a relação caótica existente entre motoristas, pedestres e ciclistas no trânsito das cidades. Dados os fatos, percebe-se uma necessidade urgente da sociedade em políticas públicas que visem informar a população acerca de seus direitos e deveres no trânsito e desmistificar conceitos equivocados para, enfim, reduzir os índices preocupantes de acidentes de trânsito no país.

A questão do trânsito é frequentemente abordada em cursos de Engenharia Civil, por exemplo. Em sua graduação, os futuros engenheiros civis aprendem disciplinas como Planejamento de Transportes, Engenharia de Tráfego e Segurança Viária. Nessas disciplinas, eles têm contato com o Código de Trânsito Brasileiro, dentre outras legislações, e problematizam acerca da situação atual do trânsito nas cidades brasileiras, a fim de habilitarem-se para trabalhar na área de Engenharia de Transportes. Nesse processo, percebese então a urgência da questão e buscam-se formas de a academia contribuir com uma melhor convivência nas cidades.

As universidades têm em suas mãos ferramentas para auxiliar no fomento de políticas públicas de educação da população. Entende-se que estas, visto que são produtoras de conhecimento, têm também a missão de repassá-lo aos demais setores da sociedade, em ações conjuntas. Essa prática é definida como extensão universitária. O Conselho de Ensino, Pesquisa e Extensão da UFPR (CEPE) define, em sua Resolução $n^{\circ} 72 / 11$, a extensão universitária como "um processo educativo, cultural, científico ou tecnológico, que articula o 
ensino e a pesquisa de forma indissociável e viabiliza a relação transformadora entre a UFPR e os demais segmentos da sociedade". O fato de a extensão ser definida como uma relação transformadora deve-se aos benefícios para ambos os participantes, principalmente para discentes. Lima et al (2017) relatam o quanto uma experiência pautada na transmissão e construção do conhecimento de forma contextualizada e dinamizada, por meio da extensão universitária, pode ser transformadora aos estudantes de graduação.

O grupo PET Engenharia Civil da UFPR, percebendo a importância da educação no trânsito através de dados e de suas vivências; notando a falta de informação da população, principalmente do público infantil; e notando a necessidade de atividades extracurriculares nas áreas de Educação em Engenharia e Engenharia de Transportes na Universidade, propôs, em seu planejamento para o ano de 2018 - que, posteriormente, estendeu-se para 2019 e 2020 -, uma atividade que englobe essas áreas do conhecimento e que trabalhe o ensino, a pesquisa e a extensão de forma indissociável, trazendo aos participantes uma experiência completa de aprendizagem. O projeto foi pensado, então, satisfazendo objetivos da Portaria nº 976/2010 do Programa de Educação Tutorial (PET-MEC) dispostos na Tabela 1.

Tabela 1 - Objetivos do PET contemplados no projeto

Objetivos atendidos pelo Projeto Mitos e Verdades sobre o Trânsito
I - desenvolver atividades acadêmicas em padrões de qualidade de excelência, mediante grupos de
aprendizagem tutorial de natureza coletiva e interdisciplinar;
II - contribuir para a elevação da qualidade da formação acadêmica dos alunos de graduação;
V - estimular o espírito crítico, bem como a atuação profissional pautada pela cidadania e pela função social da
educação superior;
Fonte: Autores,

Fonte: Autores, 2020

Surge, então, o Projeto Mitos e Verdades sobre o Trânsito. A ideia inicial do projeto consiste no desenvolvimento de atividades educativas em escolas de ensino básico de Curitiba e região metropolitana com o fim de desmistificar conceitos equivocados sobre o funcionamento do trânsito na cidade e elucidar aos cidadãos infantis quais são seus direitos e deveres como usuários de transporte individual e coletivo.

Já o objetivo do projeto na formação de engenheiros é articular o ensino, a pesquisa e a extensão de forma indissociável, proporcionando aos estudantes de Engenharia Civil uma experiência acadêmica de excelência, pautada não somente na formação de um engenheiro, mas de um cidadão de senso crítico aguçado, preparando-o para lidar com desafios de sua profissão.

\section{METODOLOGIA}

Surgiu, no início, a ideia de elaborar um projeto PET com viés extensionista e que visasse a educação da população acerca de seus direitos e deveres no trânsito das cidades. Em um brainstorming, o grupo pensou em várias possibilidades de público-alvo, visto que educação no trânsito é um assunto brando e que atinge todas as faixas etárias. Uma breve pesquisa foi feita, buscando referências para a escolha. Decidiu-se começar o projeto com foco no público infantil, visto que crianças estão em fase de alfabetização e construção de caráter, o que facilita a absorção e difusão de conhecimento. O público infantil também é ideal para ações de conscientização onde se ensine a partir de exemplos. Vygotsky (1998) explica que "no processo de desenvolvimento, a criança não somente domina os conteúdos da experiência cultural, senão também os hábitos e as formas do comportamento cultural, os métodos 
culturais de raciocínio". Ou seja, é durante a infância que a criança absorve a cultura e aprende a portar-se na sociedade.

A partir do interesse em comum pelas áreas de Educação e Engenharia de Transportes e a fim de contemplar mais discentes na participação e elaboração, decidiu-se pela parceria entre o grupo PET Engenharia Civil UFPR e o Grupo de Estudos em Transportes (GET) da UFPR. Os discentes convidaram, então, a professora Márcia de Andrade Pereira Bernardinis do Departamento de Transportes (DTT-UFPR) para ser a orientadora da atividade. Assim, o projeto, inicialmente restrito ao PET, passou a também contemplar a integração entre diferentes entidades de um mesmo curso de graduação.

Além do desenvolvimento e aplicação das atividades em escolas, o grupo decidiu por criar um livreto que servisse de complemento ao conteúdo abordado, para que o público fixasse os conceitos explanados e que o material desenvolvido pudesse atingir mais pessoas além das contempladas pelas atividades presenciais.

\subsection{Pesquisa}

No início do projeto, em 2018, os discentes se dividiram em grupos de trabalho, cada um responsável por um ente do trânsito das cidades: Motoristas/Transporte Individual Motorizado, Ciclistas, Pedestres e Transporte Público; que tornaram-se capítulos do livro. O grupo optou por dar foco não só ao papel da criança no trânsito, mas também apontar atitudes equivocadas comumente feitas por adultos em cada uma dessas situações. Assim, a criança poderá, a partir do aprendizado, ser um multiplicador desta informação, apontando essas atitudes para seus responsáveis, difundindo o conhecimento adquirido, e memorizando as atitudes corretas para quando tiverem idade para ocupar tal lugar.

Deu-se início, então, a uma extensa pesquisa em fontes como o Código de Trânsito Brasileiro, artigos científicos e blogs especializados disponíveis online. Cada capítulo do livro ficou dividido em cinco tópicos: Introdução (contextualização do modal e dos assuntos abordados no capítulo), "O que é seu direito?", "O que é seu dever?", "Curiosidades" e "Atividades". Os textos, que eram apresentados à professora orientadora a cada 15 dias aproximadamente, ficaram prontos em meados de setembro de 2018.

Deu-se início, assim, à escolha de figuras que tornassem o material mais visual. A maioria dessas imagens foi retirada de bancos de imagem livres online, porém algumas das fotos foram capturadas pelos próprios discentes, fazendo com que estes exercitassem um olhar crítico sobre o trânsito da cidade, conforme visto na figura 1. Para o capítulo "Ciclistas", o grupo de trabalho contou com a ajuda da Companhia do Pedal, grupo de ciclistas de Curitiba, que capturaram imagens de suas atividades utilizando os equipamentos corretos para tal, conforme observado na figura 2 . 


\section{COBENCE de Educação em Engenharia da ABENGE}

Figura 1 - Imagens capturadas pelos discentes para o capítulo "Pedestres"
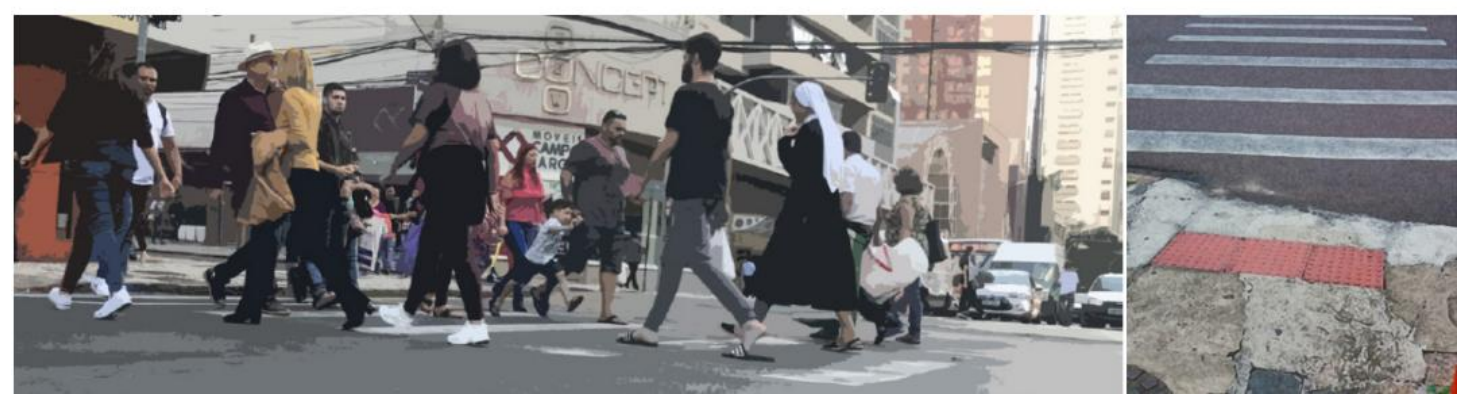

Fonte: Autores, 2020.

Figura 2 - Imagens cedidas pelo grupo Companhia do Pedal para o capítulo "Ciclistas"

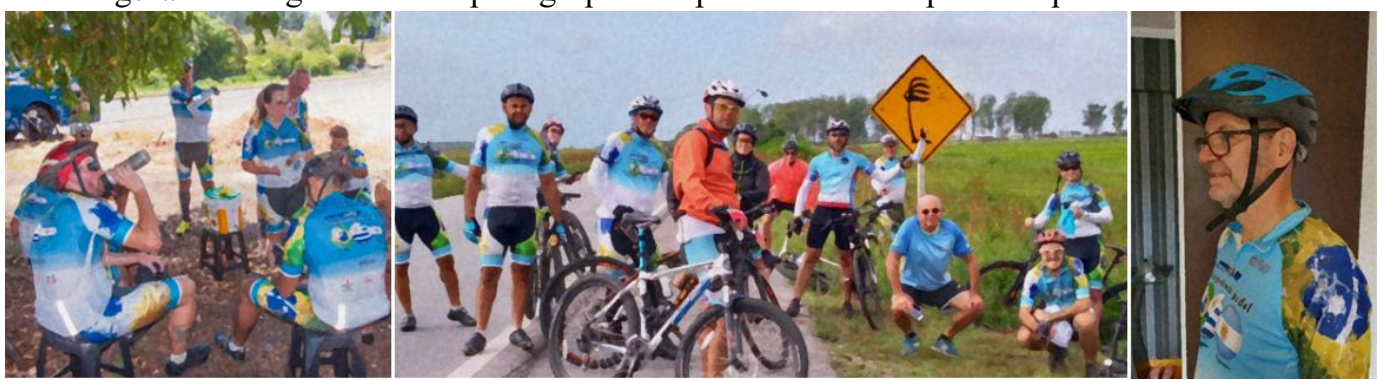

Fonte: Autores, 2020

Por fim, para o tópico "Atividades", os discentes montaram passatempos típicos do gosto infantil, como caça-palavras, jogo dos erros, ligar os pontos etc., para que o as crianças fixem o conteúdo aprendido nos textos e imagens através das brincadeiras. Todo o conteúdo do livro foi revisado e readequado para o público infantil a partir de orientações da pedagoga Maristela Gorski, que orientou o grupo a escolher a faixa etária de 6 a 10 anos como públicoalvo do livro. A partir dessas orientações, o grupo prezou por utilizar linguagem de fácil entendimento com recursos visuais e coloridos no desenvolvimento do livro. Para os termos técnicos e palavras mais complexas, uma sessão chamada "Dicionário" foi adicionada em cada capítulo.

Uma vez pronto o conteúdo, iniciou-se sua organização e projeto gráfico, feitos pelos discentes do PET. O projeto gráfico visou construir um material que tivesse um aspecto visual chamativo à faixa etária escolhida. As fotografias capturadas foram tratadas digitalmente para que ficassem com aspecto de cartum, escolheram-se fontes de texto com aspecto de escritas à mão, e cada capítulo ganhou duas cores que o identifiquem, conferindo assim um elemento lúdico no livro destinado ao público infantil. A versão final do livro foi entregue em julho de 2019.

\subsection{Extensão}

Concomitantemente ao desenvolvimento do livro, o grupo PET, juntamente com a professora orientadora, ficou responsável por conseguir o registro ISBN, a fim de regulamentar o livro e trazer credibilidade, tornando assim o patrocínio para a publicação mais atraente. O patrocínio foi cedido pelo Setor de Tecnologia da UFPR para impressão de 1000 (mil) exemplares, que serão distribuídos em escolas de ensino fundamental, juntamente com a aplicação das atividades didáticas. Busca-se, ainda, distribuí-lo e em outros pontos 
públicos interessantes na cidade de Curitiba e região metropolitana, como bibliotecas e terminais de ônibus.

Com os exemplares em mãos, os estudantes começaram então o desenvolvimento das atividades a serem aplicadas nas escolas. A proposta é visitar escolas de ensino fundamental na cidade de Curitiba e região metropolitana, que receberão também um exemplar do livro para cada aluno de 6 a 10 anos. A ideia, ainda em desenvolvimento na data de submissão deste artigo, buscará dividir os alunos em pequenos grupos e trabalhar o comportamento no trânsito a partir da adaptação de jogos populares como "amarelinha", "o mestre mandou", "pique esconde" e da criação de jogos de cartas e tabuleiro sobre o tema. A aplicação das atividades nas escolas será aberta a todas e todos os discentes do curso de Engenharia Civil da UFPR; espera-se, dessa forma, realizar ações em mais escolas e estender a experiência de extensão para estudantes não participantes dos grupos extracurriculares PET e GET, beneficiando tanto estudantes da graduação quanto as crianças impactadas pela ação.

\subsection{Ensino}

O ensino configura-se como o repasse de conhecimento de um ente a outro, e há notadamente uma grande experiência de ensino, não convencional para a estrutura de sala de aula comum nas universidades, em todas as fases do projeto. Essa experiência acontece nas formas professor-discente, discente-discente e dos discentes de engenharia para com as crianças envolvidas na ação. A complementação da leitura do livro e resolução das atividades com as atividades práticas nas escolas fornece às crianças uma experiência de ensino ativa que visa a melhor fixação desses conteúdos. Além disso, os próprios discentes têm a prática da docência, tanto quando repassam conhecimento aos demais colegas de trabalho, quanto quando o repassam às crianças por meio do livro e das atividades práticas nas escolas, fomentando o interesse de discentes pela carreira acadêmica e atendendo assim, conforme disposto no Manual de Orientações Básicas do PET (2006), um dos anseios da SESu/MEC quanto ao Programa de Educação Tutorial: formar profissionais que sejam capazes de atuar na transformação da realidade nacional, em especial como docentes e pesquisadores pósgraduados.

\section{RESULTADOS E DISCUSSÃO}

\subsection{Produto}

Como resultado já apresentado do projeto tem-se o desenvolvimento, publicação e impressão do livro Mitos e Verdades sobre o Trânsito. A autoria envolveu 23 discentes do PET e do GET e uma docente (Prof ${ }^{a}$ Márcia Bernardinis), que se dividem em 18 autores e 6 colaboradores. O patrocínio para impressão foi cedido pelo Setor de Tecnologia da UFPR, o qual abriga o Departamento de Transportes e o curso de Engenharia Civil. O livro contém 36 páginas e é dividido em Início e os quatro capítulos: Motoristas, Ciclistas, Pedestres e Transporte Público. O Início é composto pela capa; especificações do registro; créditos pela autoria, projeto gráfico e patrocínio; Sumário; Introdução, que conta quem são o PET e o GET e como surgiu o projeto; "Aos Responsáveis", explicando a importância de tratar sobre o tema Educação no Trânsito com crianças. O livro busca abordar a questão do trânsito de forma lúdica e interessante aos olhos das crianças. O resultado final das páginas iniciais Capa, Sumário, Introdução e Aos Responsáveis pode ser visto na figura 3. 
(C) COBENGE

"Os desafios para formar hoje o engenheiro do amanhã"
$\mathrm{O1}$ a $\mathrm{O3}$ de dezembro Evento On-line

Figura 3 - Páginas iniciais do livro Mitos e Verdades sobre o Trânsito

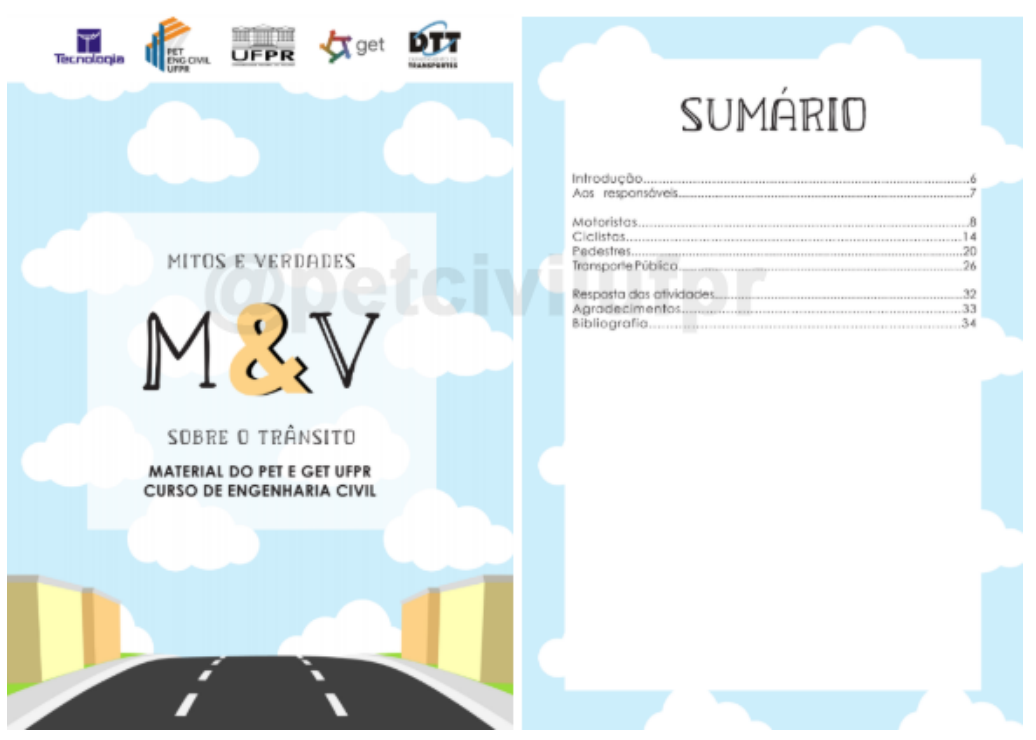

Fonte: Autores, 2020.

O conteúdo didático do livro, dividido entre as partes Motoristas, Ciclistas, Pedestres e Transporte Público, foi organizado de maneira similar para todas as partes. Cada frente ganhou duas cores complementares que as identificasse e ficou dividida pelas seções "Introdução", "O que é seu Direito?", "O que é seu Dever?", "Curiosidades" e "Atividades". O resultado final do capítulo Transporte Público pode ser observado na figura 4.

Figura 4 - Capítulo "Transporte Público"

TRANSPORTE PÚBLICO
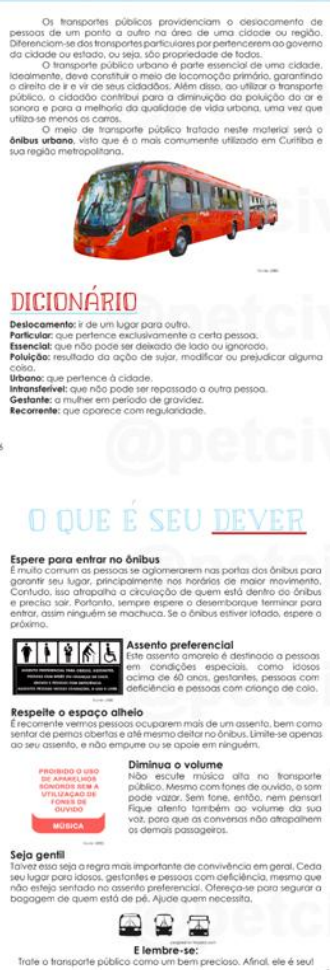

Fonte: Autores, 2020.

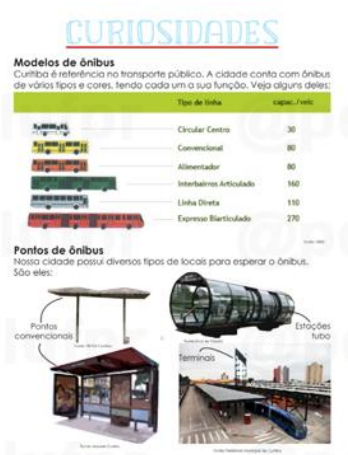

D QUE É SEU DIREITO
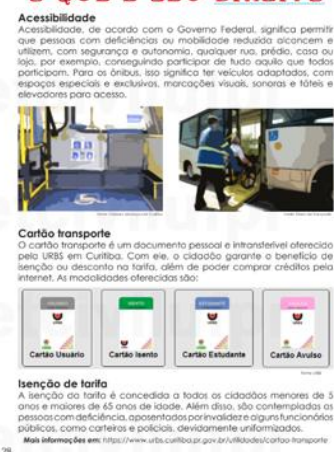

ATIVIDADES
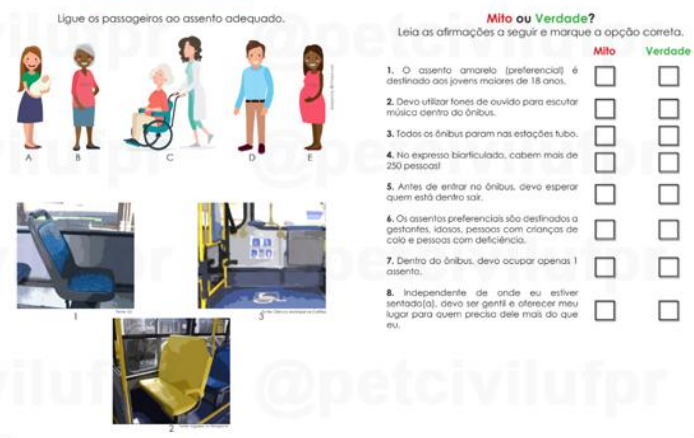


\subsection{Criação do projeto Civil nas Escolas}

Percebendo o grande impacto que o projeto "Mitos e Verdades sobre o Trânsito" teve na formação dos discentes que participaram de sua elaboração, o PET Engenharia Civil UFPR resolveu perpetuar a ideia de ações de extensão que levam temas da Engenharia Civil ao público infantil por meio da criação do projeto Civil nas Escolas. O novo projeto buscará levar ações de conscientização e projetos já existentes do PET Engenharia Civil UFPR, como a Competição de Pontes de Papel, a escolas públicas de ensino fundamental e médio de Curitiba e região metropolitana.

\section{CONSIDERAÇÕES FINAIS}

O Projeto "Mitos e Verdades sobre o Trânsito" mostra-se, portanto, uma iniciativa com grande potencial de transformação na sociedade. O trânsito nas cidades, sobretudo nas capitais, é um problema urgente do século 21, e que se deve em grande parte à falta de informação e interpretação dos transeuntes perante as normas e legislações vigentes. É fundamental que se olhe para as crianças como parte importante na melhoria dessas condições, visto que elas são cidadãs assim como os adultos. Além disso, é interessante que se façam atividades lúdicas para que as crianças aprendam fazendo e refletindo sobre. Ainda, a parte extensionista do projeto, com o contato da academia com a escola de ensino fundamental, proporciona, também, a divulgação da universidade perante a comunidade externa, motivando os alunos atingidos pelo projeto a buscarem por uma formação superior no futuro.

Ademais, o projeto "Mitos e Verdades sobre o Trânsito" mostrou-se uma excelente ferramenta de ensino-aprendizagem para os estudantes de Engenharia Civil. Os discentes envolvidos no projeto relataram grande satisfação em relação aos resultados do projeto. Entender a questão do trânsito através da necessidade da população para construir o livro e as atividades práticas contribuiu para a formação do senso crítico dos futuros engenheiros acerca da temática. A partir da pesquisa mais aprofundada acerca de um tema abordado em sala de aula, e posteriormente da extensão desse conhecimento adquirido à comunidade externa à universidade, visando uma melhora social, os estudantes puderam experimentar uma experiência completa de graduação, que busca formá-los não só tecnicamente, mas como seres críticos e pensantes, compromissados com a melhoria da sociedade em que vivem.

\section{REFERÊNCIAS}

BRASIL. Lei no 9.503, de 23 de setembro de 1997. Institui o Código de Trânsito Brasileiro. Diário Oficial da União, Brasília, DF, 24 set. 1997.

BRASIL. Ministério da Educação. Manual de Orientações - PET. Disponível em: http://portal.mec.gov.br/pet/manual-de-orientacoes. Acesso em 29 maio 2020.

BRASIL. Portaria no 343, de 24 de Abril de 2013. Altera dispositivos da Portaria MEC no 976 de 27 de Julho de 2010. Diário Oficial da União, Brasília, DF, n. 79, 25 abr. 2013. Disponível em: http://portal.mec.gov.br/pet/legislacao. Acesso em 29 maio 2020.

BRASIL. Portaria no 976, de 27 de Julho de 2010. Institui o Programa de Educação Tutorial. Diário Oficial da União, Brasília, DF, n. 212, 31 out. 2013. Disponível em: http://portal.mec.gov.br/pet/legislacao. Acesso em 29 maio 2020. 
(C) COBENCE

"Os desafios para formar hoje o engenheiro do amanhã"

COLACO, Veriana de Fátima Rodrigues. Processos interacionais e a construção de conhecimento e subjetividade de crianças. Psicol. Reflex. Crit., Porto Alegre, v. 17, n. 3, p. 333-340, 2004.Disponível em http://www.scielo.br/scielo.php?script=sci_arttext\&pid=S010279722004000300006\&lng=pt\&nrm=iso. Acesso em 26 maio 2020.

DETRAN-PR. Estatísticas de Trânsito - Ano de 2010. Disponível em: http://www.detran.pr.gov.br/arquivos/File/estatisticasdetransito/DadosEstatisticos2010.pdf.

Acesso em 1 junho 2020.

IGARASHI, A.V.; FERREIRA, G.P.; BERNARDINIS, M.A.P.; et al. Mitos e Verdades sobre o Trânsito. Tecnologia UFPR. Curitiba, 2019. Disponível em: https://drive.google.com/file/d/120Bq4OEgEUrOETPXCtUlPCpApokDOQjb/view?usp=shari ng. Acesso em 29 maio 2020.

JORGE, M.H.P.M.; MARTINS, C.B.G. A criança, o adolescente e o trânsito: algumas reflexões importantes. Rev. Assoc. Med. Bras. São Paulo, 2013. Disponível em: https://doi.org/10.1016/j.ramb.2012.11.007. Acesso em 29 maio 2020.

LIMA, J.E.C.; SILVA, I.R.N.; NASCIMENTO, P.F.; et al. A IMPORTÂNCIA DA EXTENSÃO UNIVERSITÁRIA NA FORMAÇÃO PROFISSIONAL: EXPERIÊNCIA VIVENCIADA POR ALUNOS DO CURSO DE FARMÁCIA. II Congresso Brasileiro de Ciências da Saúde. Campina Grande, 2017. Disponível em: <http://www.editorarealize.com.br/revistas/conbracis/trabalhos/TRABALHO_EV071_MD1_ SA3_ID2191_14052017154833.pdf>. Acesso em 29 maio 2020.

VYGOTSKY, L. S. El desarrollo cultural del niño y otros textos ineditos. Buenos Aires: Almagestos, 1998. (Original publicado em 1928). 


\title{
THE MAKING OF EDUCATIVE ACTIONS FOR CHILDREN ABOUT RIGHTS AND DUTIES ON TRAFFIC BY STUDENTS OF CIVIL ENGINEERING OF UFPR
}

\begin{abstract}
The chaotic traffic in the cities of Brazil is turning more lethal each year, especially for the young. The problems in traffic occur, in parts, due to the misunderstanding of the law, as well as the population's rights and duties. Willing to contribute to minimizing the number of traffic accidents in the city of Curitiba $(P R)$ and its Metropolitan area, PET Engenharia Civil UFPR (Tutorial Education Program in Civil Engineering of Federal University of Paraná - Brazil) has created the "Myths and Facts about Traffic" project. The students use their knowledge from Transport Engineering related disciplines to build an educative book and practical activities for 6-10 years old children in public schools of the city. As a result, beyond the product itself, the students have lived an extra class experience that articulates teaching, research and extension, unusual on conventional teaching structures that added hard and soft skills to their formation, both equally fundamental in the forming of the engineering of tomorrow.
\end{abstract}

Keywords: Traffic education. Transports Engineering. Tutorial Education Program. 